\title{
The stability of soft drinks intake from adolescence to adult age and the association between long-term consumption of soft drinks and lifestyle factors and body weight
}

\author{
Elisabeth Kvaavik*, Lene Frost Andersen and Knut-Inge Klepp \\ Department of Nutrition, Faculty of Medicine, University of Oslo, PO Box 1046 Blindern, N-0316 Oslo, Norway
}

Submitted 7 January 2004: Accepted 17 May 2004

\begin{abstract}
Objectives: To investigate the tracking of sugar-sweetened, carbonated soft drinks intake from age 15 to 33 years and the association between this intake and lifestyle factors and body weight.

Design: A longitudinal study with 18-20 years of follow-up. Data about diet, physical activity, smoking and dieting were collected in 1981/1979, 1991 and 1999. Body weight and height were measured in 1981/1979 and self-reported in 1999.

Setting: Oslo, Norway.

Subjects: Four hundred and twenty-two men and women.

Results: Tracking of soft drinks intake from adolescence into early adulthood (age 25 years) and from early adulthood into later adulthood (33 years) was moderate to high, while tracking from adolescence into later adulthood was low. Comparing those reporting a high intake of soft drinks in both 1991 and 1999 with those reporting a low intake at both times, male long-term high consumers were more likely to smoke ( 48 vs. $21 \%, P=0.002)$ and reported higher intakes of energy (12.2 vs. $10.2 \mathrm{MJ} \mathrm{day}^{-1}$, $P=0.005)$ and sugar (142 vs. $\left.50 \mathrm{~g} \mathrm{day}^{-1}, P<0.001\right)$ in 1999 than did long-term low consumers. Women high consumers were less likely to be physically active (14 vs. $42 \%, P=0.03$ ) and had higher sugar intake ( 87 vs. $41 \mathrm{~g} \mathrm{day}^{-1}, P<0.001$ ) in 1999 than did women low consumers. There were no differences in body mass index, overweight or obesity in 1999 between long-term high and low consumers.

Conclusion: In this study, stability of soft drinks intake from age 15 to 25 years and from age 25 to 33 years was moderate to high, while from age 15 to 33 years it was low. Soft drinks intake from age 25 to 33 years was associated with smoking and physical inactivity, but not with body weight.
\end{abstract}

Keywords Soft drinks consumption Longitudinal study Young adults Body weight
Consumption of soft drinks has increased dramatically in Norway over past decades ${ }^{1-3}$. In an average Norwegian household in 1996-98, sugar-sweetened, carbonated soft drinks contributed $19 \%$ of the total intake of added sugar (K Trygg, personal communication, Department of Nutrition, University of Oslo, 23 January 2003). Worldwide the consumption of added sugars has increased considerably over recent years, with beverages shown to be a major contributor ${ }^{4}$. Associations between healthrelated behaviours such as smoking, physical inactivity, alcohol use and unhealthy dietary habits have previously been demonstrated ${ }^{5-7}$. However, associations between the intake of sugar-sweetened soft drinks and other health-related behaviours have been less studied.

Lately sugar-sweetened soft drinks intake has been in focus for its potential role as a risk factor for overweight and obesity ${ }^{8-12}$. During the last few decades, adult body weight has increased in all Western countries ${ }^{13,14}$. In Norway, the prevalence of obesity (body mass index
$(\mathrm{BMI}) \geq 30 \mathrm{~kg} \mathrm{~m}^{-2}$ ) increased from 9.6 to $14.0 \%$ among 40 year-old men and from 8.8 to $11.6 \%$ among women of the same age between 1994-96 and 1997-99 ${ }^{15}$. Since body weight is a result of health-related behaviours over time, the stability of behaviours suspected to be risk factors for overweight is of interest.

Tracking can be defined as the stability (consistent classification) of health-related behaviours over time or as stability in rank at the group level ${ }^{16}$. Few prospective studies have investigated tracking of diet ${ }^{16-20}$, and only the Norwegian study by Lien et al. has investigated the tracking of sugar-sweetened, carbonated soft drinks intake $^{19}$. These authors reported that intake of sugarcontaining soft drinks was stable from age 14 to 21 years; the group reporting the most frequent consumption at age 14 still reported the most frequent consumption at age 21 . Consumption frequency for soft drinks intake among those having soft drinks less than three times per week at age 14 was on average three times per week at age 21 . 
Among those having soft drinks daily at age 14, the consumption frequency was on average seven times per week seven years later ${ }^{19}$.

The objectives of the present study were to investigate tracking of sugar-sweetened, carbonated soft drinks intake from age 15 to 33 years and the association between longterm (from age 25 to 33 years) intake of soft drinks and smoking, physical activity, added sugar intake, total energy intake and body weight at age 33 years.

\section{Methods}

\section{Design}

The Oslo Youth Study baseline survey was conducted in 1979 , with participants in the 5 th to 7 th grade (mean age 13 years, range 11-16 years) from six schools in Oslo, Norway.

Participants completed a questionnaire at school and underwent a brief health examination, including measurements of height and weight. A nearly identical follow-up study was conducted in 1981. In 1991 and 1999 participants completed postal questionnaires. For this paper, the 1981 survey was chosen as the baseline survey as health-related habits were regarded as being more established at age 15 than at age 13 . To increase the sample size, 1981 data were supplemented with 1979 data for 76 participants who did not participate in 1981.

As part of the study, an intervention was implemented and evaluated. Both children who received the intervention and the controls are included in this study. The intervention is described in detail elsewhere ${ }^{21}$.

The study was approved by the Norwegian Data Inspectorate, as well as the City of Oslo's health authorities.

\section{Subjects}

This paper includes information from participants who took part in surveys in 1981/1979, 1991 and 1999 (Fig. 1). While there were 1086 eligible subjects in 1981, this number was reduced to 915 in 1999 due to deaths $(n=6)$, unknown addresses $(n=115)$, refusals to participate $(n=21)$ and emigration $(n=29)$. Of the 443 respondents participating at all three time points, 21 were excluded, resulting in a participation rate of $46 \%$ (422/915).

\section{Questionnaire in 1979 and 1981}

The questionnaire used in 1979 and 1981 included two questions about intake of carbonated soft drinks: 'Did you drink carbonated soft drinks yesterday?' with the response alternatives 'no', 'yes, at school' and 'yes, at home', and 'Did you drink carbonated soft drinks with added sugar last week?' with the response alternatives 'no' and 'yes'. Three levels of soft drinks intake were made by combining these two questions: (1) 'previous day' - drank carbonated soft drinks the previous day at home and/or at school and during the previous week; (2) 'past week' drank carbonated soft drinks during the past week but not the previous day, or the previous day but not the past week; and (3) 'never/seldom' - drank no carbonated soft drinks during the previous week or the past day.

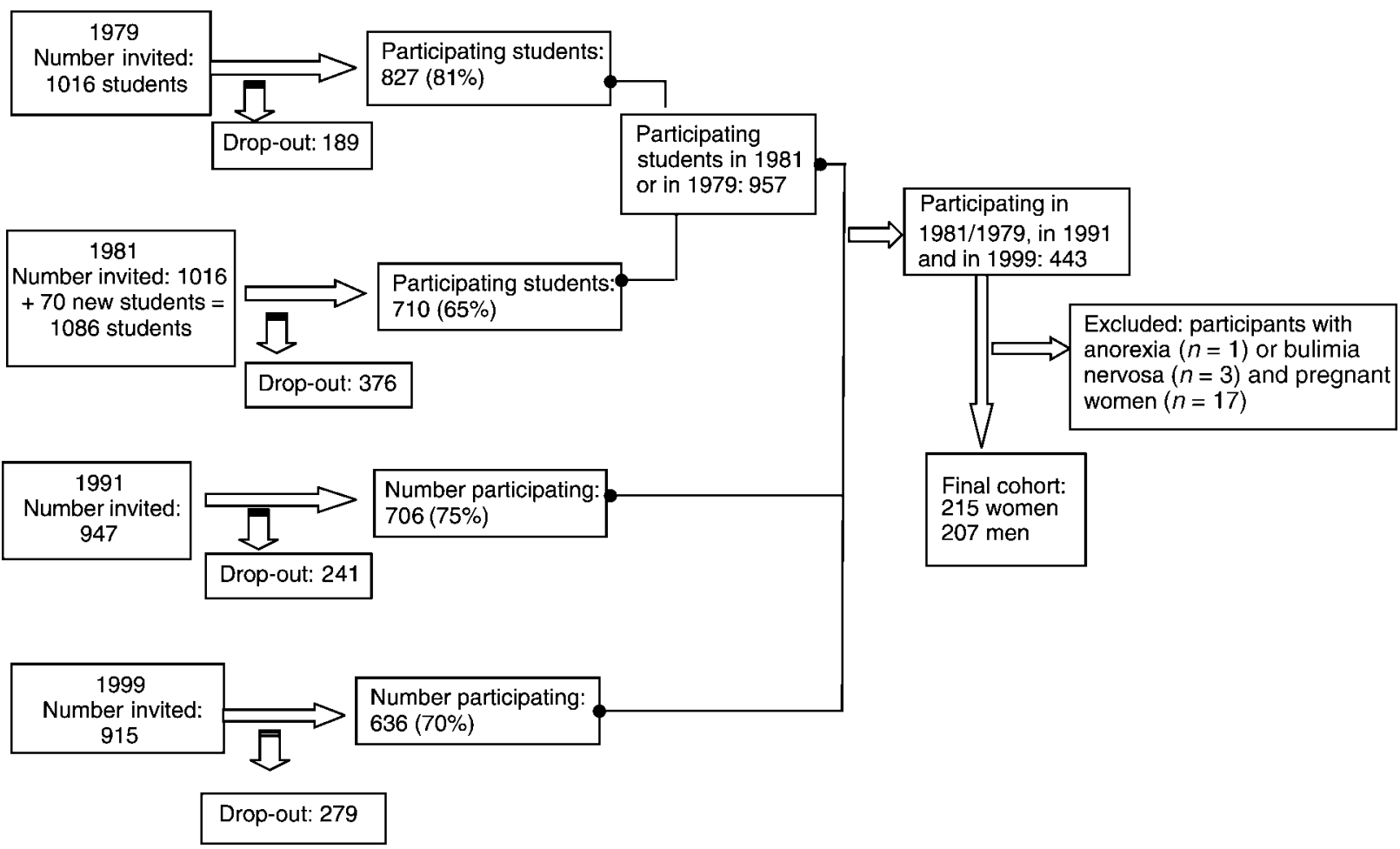

Fig. 1 Flow chart showing participation and participation rates, The Oslo Youth Study 
The questionnaire also included questions about leisure-time physical activity and smoking. Leisure-time physical activity was defined as at least 30 min of physical activity during leisure time of an intensity to produce sweating and being short of breath, and frequencies ranged from less than twice a month to daily. Cigarette smoking frequency ranged from never to daily. Adolescent participants were defined as regular smokers if they smoked cigarettes at least weekly.

\section{Questionnaires in 1991 and 1999}

The 1991 questionnaire included one question about intake of sugar-sweetened, carbonated soft drinks and one regarding artificially sweetened soft drinks. The five frequency alternatives were 'never/seldom', 'one to two times per week', 'three to six times per week', 'once daily' and 'more than once daily'.

The 1999 questionnaire was a validated semi-quantitative food-frequency questionnaire aimed to gain information about a participant's whole $\operatorname{diet}^{22,23}$. The questionnaire included one question regarding sugarsweetened and one regarding artificially sweetened, carbonated soft drinks, assessing both frequency and amount of intake. The 10 frequency categories were categorised as follows. 'Never', 'less than one', 'one', 'two' and 'three times per month' were categorised as 'never/ seldom'; 'one' and 'two to three times per week' were categorised as 'one to three times per week'; 'four to five times per week' was kept as is; 'six to seven times per week' was categorised as 'once daily'; 'eight or more times per week' was categorised as 'more than daily'. Six alternatives determined the amount of carbonated soft drinks consumed, and ranged from 0.25 to 1.5 litres. In addition, grams of carbonated soft drinks per day, intake of added sugar, energy intake and percentage of energy from sugar are reported for 1999.

Basal metabolic rate (BMR) was calculated from standard formulas based on weight, age and $\operatorname{sex}^{24}$. A comparison of energy intake (EI) with estimates of BMR was used to calculate the number of respondents who underreported their energy intake from the questionnaire used in 1999. EI/BMR ratio less than 1.35 may indicate underreporting of energy intake $\mathrm{e}^{24-26}$.

The questions regarding leisure-time physical activity and smoking in the questionnaires used in 1991 and 1999 were the same as in 1981/1979. However, in 1991 and 1999, a regular smoker was defined as someone smoking daily. In 1991 and 1999 dieting was assessed by the question: 'Have you tried to lose weight during the last three months?' with response alternatives 'no' and 'yes'.

\section{Height and weight}

In 1981/1979, body weight and height were measured at school by project staff. In 1999, body weight and height were self-reported.

\section{Long-term consumption of sugar-sweetened, carbonated soft drinks}

In 1991 and 1999 participants were grouped into two groups based on their reported frequency of sugarsweetened, carbonated soft drinks consumption. Soft drinks intake of two or fewer times a week in 1991 and three or fewer times a week in 1999 was categorised as a low intake, while an intake of three times a week or more in 1991 and four times or more in 1999 was categorised as a high intake. A subject was defined as a 'long-term low consumer' if he/she reported low intake in both 1991 and 1999 and as a 'long-term high consumer' if he/she reported high intake in both 1991 and 1999. If the intake changed from high to low or vice versa between 1991 and 1999, the subject was categorised as an inconsistent consumer'.

\section{Statistical analysis}

Unpaired $t$-tests and chi-square tests were used to compare participants with those who dropped out of the survey, and to compare women and men with respect to dependent and independent variables in 1981/1979, 1991 and 1999. The unpaired $t$-test and Pearson's bivariate correlation coefficient were used in the tracking analyses. Pearson's bivariate correlation coefficients were computed between the sugar-sweetened, carbonated soft drinks intake categories presented (Table 2). Analyses of variance (UNIANOVA) were used in comparing long-term low and high consumers of sugar-sweetened, carbonated soft drinks with respect to the prevalence of leisure-time physical activity, smoking, dieting and energy underreporting, as well as mean intake of sugar-sweetened, carbonated soft drinks, energy and sugar and mean BMI reported in 1999.

Multiple logistic regression analysis was used to study overweight and obesity in relation to consumption of sugar-sweetened soft drinks during 1991-1999. An unadjusted model and a model adjusted for adolescent BMI are presented. We also estimated the odd ratios adjusting for other factors known to be associated with body weight (energy intake, leisure-time physical activity, smoking, dieting and energy underreporting). These models are not presented since the results did not differ from those of the models presented. The models were tested for interaction by intervention status. As no interaction effects were seen, the intervention group and the control group were combined in the analyses presented here. All results are presented for men and women separately.

The analyses presented used the 1981 baseline data supplemented with data for 1979 participants $(n=76)$ who did not participate in 1981. However, all analyses were repeated using the 1981 data only. The results did not differ between the two sets of baseline data, but the statistical power was reduced using 1981 data only. 
The statistical software package SPSS 11.0 for Windows (SPSS Inc., Chicago, IL, USA) was used in all analyses.

\section{Attrition analysis}

A total of 443 out of 957 who participated in 1981/1979 also responded in 1991 and 1999. Comparing the 443 responders with the 514 drop-outs revealed that, in $1981 / 1979$, the responders were older ( 14.7 vs. 14.3 years, $P<0.001$ ), less likely to be male ( 46.7 vs. $57.8 \%$ male, $P=0.001)$ and less likely to smoke (11.6 vs. $19.2 \%$ smokers, $P=0.002$ ) than the drop-outs. No significant differences existed between responders and drop-outs in sugar-sweetened, carbonated soft drinks intake, leisuretime physical activity or BMI in 1981/1979.

\section{Results}

Data for all variables investigated in this study in 1981/1979, 1991 and 1999 are presented in Tables 1 and 2. At age 25 (1991) and 33 (1999) years, women reported lower intake frequencies of sugar-sweetened, carbonated soft drinks than did men.

In 1991 , more women than men ( 34 vs. $23 \%, P=0.01$ ) drank artificially sweetened, carbonated soft drinks three times per week or more. In 1991, 19\% of women and 13\% of men had artificially sweetened, carbonated soft drinks four times per week or more $(P=0.07)$. In 1999 , men reported more than twice the daily consumption of sugarsweetened, carbonated soft drinks than did women, reflecting both the higher frequency and larger amounts per event: 347 versus $131 \mathrm{~g} \mathrm{day}^{-1}$.

The frequency of sugar-sweetened, carbonated soft drinks intake in 1991 was lower among those reporting a low intake in 1981/1979 compared with those who reported a high intake in 1981/1979 (Table 3). Furthermore, the amount and frequency of sugar-sweetened, carbonated soft drinks intake in 1999 were lower among those consuming such beverages less than three times weekly in 1991, compared with those reporting consuming soft drinks at least three times weekly in 1991. This was observed for both men and women (Table 3). The correlation coefficient between frequency of sugarsweetened, carbonated soft drinks intake in 1991 and 1999 was 0.33 and 0.44 for women and men, respectively $(P<0.001$ for both $)$.

Among women who reported never/seldom consuming sugar-sweetened, carbonated soft drinks in 1981/1979, $57 \%$ had such beverages never/seldom in 1991, while $28 \%$ of these women reported a daily intake in 1991. The corresponding figures for men were $39 \%$ and $41 \%$, respectively. Among women who reported to have had sugar-sweetened, carbonated soft drinks the previous day in 1981/1979, 31\% drank such beverages daily and $47 \%$ never/seldom in 1991. For men, corresponding figures were $53 \%$ and $16 \%$, respectively. Among women who had sugar-sweetened, carbonated soft drinks never/seldom in 1981/1979, 60\% also reported such beverages never/seldom in 1999 while $13 \%$ of these women had a daily

Table 1 Differences between men and women with respect to variables investigated in 1981/1979, 1991 and 1999, The Oslo Youth Study

\begin{tabular}{|c|c|c|c|c|}
\hline & & Women & Men & $P$-value \\
\hline \multirow[t]{5}{*}{$1981 / 1979$} & & $(n=236)$ & $(n=207)$ & \\
\hline & Age (years), mean (range) & $14.6(11.0-17.0)$ & $14.7(11.0-17.0)$ & 0.362 \\
\hline & BMI $\left(\mathrm{kg} \mathrm{m}^{-2}\right)$, mean $(\mathrm{SD})^{*}$ & $19.8(2.5)$ & $19.5(2.6)$ & 0.542 \\
\hline & LTPA at least twice weekly (\%)† & 56.0 & 66.7 & 0.015 \\
\hline & Smoking (\% weekly smokers) $\ddagger$ & 15.1 & 7.5 & 0.029 \\
\hline \multirow[t]{5}{*}{1991} & & $(n=236)$ & $(n=207)$ & \\
\hline & Age (years), mean (range) & $24.9(23.0-27.0)$ & $25.1(23.0-27.0)$ & 0.108 \\
\hline & LTPA at least twice weekly (\%)† & 43.9 & 48.2 & 0.392 \\
\hline & Smoking (\% daily smokers) $\ddagger$ & 45.3 & 34.5 & 0.041 \\
\hline & Tried to lose weight last 3 months? (\% yes) $\dagger$ & 25.8 & 12.3 & $<0.001$ \\
\hline \multirow[t]{13}{*}{1999} & & $(n=215) \ddagger$ & $(n=207)$ & \\
\hline & Age (years), mean (range) & $32.9(31.0-35.0)$ & $33.1(31.0-35.0)$ & 0.168 \\
\hline & LTPA at least twice weekly (\%)† & 36.6 & 37.1 & 0.923 \\
\hline & Smoking (\% daily smokers) $\dagger$ & 33.3 & 28.6 & 0.299 \\
\hline & Tried to lose weight last 3 months? (\% yes) $\dagger$ & 27.7 & 15.5 & 0.003 \\
\hline & BMI $\left(\mathrm{kg} \mathrm{m}^{-2}\right)$, mean $(\mathrm{SD})^{\star}$ & $23.4(4.1)$ & $25.6(3.9)$ & $<0.001$ \\
\hline & Overweight, $\mathrm{BMI} \geq 25 \mathrm{~kg} \mathrm{~m}^{-2}(\%) \dagger$ & 26.5 & 53.2 & $<0.001$ \\
\hline & Obese, $\mathrm{BMI} \geq 30 \mathrm{~kg} \mathrm{~m}^{-2}(\%) \dagger$ & 8.1 & 9.0 & 0.744 \\
\hline & $\begin{array}{l}\text { Sugar-sweetened, carbonated soft drinks }\left(\mathrm{g} \mathrm{day}^{-1}\right) \text {, } \\
\text { mean (SD)* }\end{array}$ & $131(192)$ & $347(557)$ & $<0.001$ \\
\hline & Added sugar $\left(\mathrm{g} \mathrm{day}^{-1}\right)$, mean $(\mathrm{SD})^{\star}$ & $53.4(44.4)$ & $76.0(66.2)$ & $<0.001$ \\
\hline & Energy $\left(\mathrm{kJ} \mathrm{day}^{-1}\right)$, mean $(\mathrm{SD})^{\star}$ & 8235 (2857) & $10668(3455)$ & $<0.001$ \\
\hline & $\%$ Energy from sugar, mean (SD)* & $10.3(6.2)$ & $11.5(7.9)$ & 0.105 \\
\hline & $\mathrm{El} / \mathrm{BMR}<1.35(\%)$ & 52 & 54 & 0.670 \\
\hline
\end{tabular}

BMI - body mass index; SD - standard deviation; LTPA - leisure-time physical activity; El/BMR - ratio of energy intake to basal metabolic rate.

${ }^{*}$ Genders compared with $t$-test.

† Genders compared with chi-square test.

$\ddagger$ Seventeen pregnant women, three with bulimia and one with anorexia are excluded from the analyses. 
Table 2 Frequency of sugar-sweetened, carbonated soft drinks consumption in 1981/1979, 1991 and 1999 by men and women (\%), The Oslo Youth Study

\begin{tabular}{llccc}
\hline & & Women & Men & $P$-value \\
\hline $1981 / 1979$ & & $(n=236)$ & $(n=207)$ & \\
& & 22.9 & 21.7 & \\
& Never/seldom & 37.3 & 36.7 & \\
& Past week & 39.8 & 41.5 & 0.353 \\
& Previous day & $(n=236)$ & $(n=207)$ & \\
& & 54.3 & 25.6 & \\
& Never/seldom & 21.6 & 27.6 & \\
& $1-2$ times per week & 10.8 & 25.6 & \\
& 3-6 times per week & 9.5 & 9.9 & \\
& Once daily & 3.9 & 11.3 & $<0.001$ \\
& More than once daily & $(n=215)$ & $(n=207)$ & \\
& & 46.3 & 27.1 & \\
& Never/seldom & 30.3 & 38.7 & \\
& 1-3 times per week & 10.4 & 11.1 & \\
& 4-5 times per week & 10.0 & 10.6 & \\
& Once daily & 3.0 & 12.6 & $<0.001$
\end{tabular}

*Chi-square test for sex differences across all consumption groups.

intake in 1999. The corresponding figures for men were $35 \%$ and $19 \%$, respectively. Finally, among women who reported to have had sugar-sweetened, carbonated soft drinks the previous day in 1981/1979, only 16\% drank such beverages daily in 1999, while 40\% drank soft drinks never/seldom in 1999. Corresponding figures for men were $25 \%$ and $23 \%$, respectively.

The covariation between levels of long-term ( 25 to 33 years of age) consumption of sugar-sweetened, carbonated soft drinks and leisure-time physical activity, smoking, dieting, energy and sugar intake, as well as energy underreporting and BMI in 1999, are presented in Table 4. The soft drinks intake from age 25 to 33 years of age was used because of the weak tracking of soft drinks intake from adolescence to adulthood. Differences between the consumption groups were observed for leisure-time physical activity in 1999 among women, smoking prevalence, energy intake and energy underreporting in 1999 among men, and intake of sugar-sweetened soft drinks and sugar in 1999 among both men and women. No differences were seen between the consumption groups with regard to dieting or mean BMI in 1999. The figures for the inconsistent consumers were, for all these variables, between the figures seen for the long-term low and high consumers.

Table 5 presents the odds ratios for being overweight and obese in 1999 among inconsistent and long-term high consumers of sugar-sweetened, carbonated soft drinks compared with the long-term low consumers. The odds ratio of being obese was somewhat higher for men among long-term high consumers compared with long-term low consumers; however, the results were not statistically significant. Further adjustments for variables known to influence body weight introduced only minor changes to these results.

\section{Discussion}

The results from this study showed that intake of soft drinks from early adulthood (age 25 years) into later adulthood (age 33) for both men and women was relatively stable while the stability in soft drinks intake from adolescence (age 15) into later adulthood (age 33) was low. Long-term (age 25 to 33 years) high consumers of sugar-sweetened, carbonated soft drinks had a higher energy intake, a lower proportion was physically active and a higher proportion smoked regularly compared with long-term low consumers. We did not observe a significant association between long-term intake of sugar-sweetened, carbonated soft drinks and body weight.

Previous studies of food choices have demonstrated a moderate to high degree of tracking ${ }^{16-20}$. The results from our study indicate, however, a low stability from adolescence into later adulthood and a moderate stability from adolescence into early adulthood. The moderate

Table 3 Sugar-sweetened, carbonated soft drinks intake in 1991 and 1999 by frequency in 1981/1979, and in 1999 by frequency in 1991 (mean (standard deviation)), The Oslo Youth Study

\begin{tabular}{|c|c|c|c|c|c|c|}
\hline \multirow{3}{*}{$\begin{array}{l}\text { Sugar-sweetened, } \\
\text { carbonated soft drinks } \\
\text { intake at follow-up }\end{array}$} & \multicolumn{6}{|c|}{ Sugar-sweetened, carbonated soft drinks intake, frequency in $1981 / 1979$} \\
\hline & \multicolumn{3}{|c|}{ Women } & \multicolumn{3}{|c|}{ Men } \\
\hline & $\begin{array}{c}\text { Seldom/past } \\
\text { week }(n=132)\end{array}$ & $\begin{array}{l}\text { Previous day } \\
\quad(n=83)\end{array}$ & $P$-value* & $\begin{array}{c}\text { Seldom/past } \\
\text { week }(n=121)\end{array}$ & $\begin{array}{c}\text { Previous } \\
\text { day }(n=86)\end{array}$ & $P$-value* \\
\hline Times weekly in 1991 & $1.6(2.5)$ & $2.5(3.3)$ & 0.029 & $2.8(2.9)$ & $4.2(3.5)$ & 0.004 \\
\hline Times weekly in 1999 & $1.9(3.2)$ & $2.4(2.6)$ & 0.263 & $3.5(4.1)$ & $4.2(4.6)$ & 0.239 \\
\hline \multirow[t]{4}{*}{ Grams daily in 1999} & $121(211)$ & $144(165)$ & 0.410 & $319(538)$ & $402(601)$ & 0.320 \\
\hline & \multicolumn{6}{|c|}{ Sugar-sweetened, carbonated soft drinks intake, frequency in 1991} \\
\hline & \multicolumn{3}{|c|}{ Women } & \multicolumn{3}{|c|}{ Men } \\
\hline & $\begin{array}{c}<3 \text { times } \\
\text { weekly }(n=158)\end{array}$ & $\begin{array}{c}\geq 3 \text { times } \\
\text { weekly }(n=53)\end{array}$ & $P$-value* & $\begin{array}{l}\quad<3 \text { times } \\
\text { weekly }(n=108)\end{array}$ & $\begin{array}{c}\geq 3 \text { times } \\
\text { weekly }(n=95)\end{array}$ & $P$-value* \\
\hline $\begin{array}{l}\text { Times weekly in } 1999 \\
\text { Grams daily in } 1999\end{array}$ & $\begin{array}{l}1.5(2.2) \\
88(138)\end{array}$ & $\begin{array}{c}3.9(4.1) \\
252(268)\end{array}$ & $\begin{array}{l}<0.001 \\
<0.001\end{array}$ & $\begin{array}{l}2.4(3.2) \\
187(297)\end{array}$ & $\begin{array}{c}5.3(4.9) \\
537(719)\end{array}$ & $\begin{array}{l}<0.001 \\
<0.001\end{array}$ \\
\hline
\end{tabular}

*Unpaired $t$-test for differences between consumption groups. 
Table 4 Health-related behaviours, energy underreporting and body mass index (BMI) in 1999 in relation to level of long-term (1991-1999) consumption of sugar-sweetened, carbonated soft drinks by sex, The Oslo Youth Study

\begin{tabular}{|c|c|c|c|c|}
\hline & $\begin{array}{l}\text { Long-term low } \\
\text { consumers* }^{*}\end{array}$ & $\begin{array}{l}\text { Inconsistent } \\
\text { consumers }^{*}\end{array}$ & $\begin{array}{l}\text { Long-term high } \\
\text { consumers* }\end{array}$ & $P$-value $\dagger$ \\
\hline Women $(n=196)$ & $(n=123)$ & $(n=51)$ & $(n=22)$ & \\
\hline LTPA at least twice weekly (\%) & 42 & 31 & 14 & 0.029 \\
\hline Smoking (\% daily smokers) & 28 & 45 & 41 & 0.070 \\
\hline Cigarettes per day among smokers, mean (SD) & $10.5(5.3)$ & $10.7(5.8)$ & $13.0(5.7)$ & 0.472 \\
\hline Tried to lose weight last 3 months? (\% yes) & 30 & 24 & 23 & 0.642 \\
\hline $\begin{array}{l}\text { Sugar-sweetened, carbonated soft } \\
\text { drinks intake }\left(\mathrm{g} \mathrm{day}^{-1}\right) \text {, mean (SD) }\end{array}$ & $43(60)$ & $192(180)$ & $470(271)$ & $<0.001$ \\
\hline Energy intake (MJ day $\left.{ }^{-1}\right)$, mean (SD) & $8.1(2.6)$ & $8.7(3.2)$ & $8.7(2.7)$ & 0.365 \\
\hline Sugar intake $\left(\mathrm{g} \mathrm{day}^{-1}\right)$, mean (SD) & $41(31)$ & $74(58)$ & $87(37)$ & $<0.001$ \\
\hline$\%$ Energy from sugar, mean (SD) & $8.1(4.7)$ & $13.4(6.4)$ & $17.9(6.1)$ & $<0.001$ \\
\hline $\mathrm{El} / \mathrm{BMR}<1.35(\%)$ & 54 & 46 & 36 & 0.233 \\
\hline BMI $\left(\mathrm{kg} \mathrm{m}^{-2}\right)$, mean (SD) & $23.4(4.1)$ & $23.0(3.9)$ & $24.0(5.3)$ & 0.627 \\
\hline $\operatorname{Men}(n=192)$ & $(n=80)$ & $(n=67)$ & $(n=45)$ & \\
\hline LTPA at least twice weekly (\%) & 34 & 43 & 31 & 0.342 \\
\hline Smoking (\% daily smokers) & 21 & 22 & 48 & 0.002 \\
\hline Cigarettes per day among smokers, mean (SD) & $13.5(6.8)$ & $10.5(6.1)$ & $16.9(7.3)$ & 0.026 \\
\hline Tried to lose weight last 3 months? ( $\%$ yes) & 13 & 18 & 13 & 0.692 \\
\hline $\begin{array}{l}\text { Sugar-sweetened, carbonated soft } \\
\text { drinks intake }\left(\mathrm{g} \mathrm{day}^{-1}\right) \text {, mean (SD) }\end{array}$ & $82(77)$ & $257(342)$ & $965(814)$ & $<0.001$ \\
\hline Energy intake (MJ day $\left.{ }^{-1}\right)$, mean (SD) & $10.2(3.4)$ & $10.5(3.2)$ & $12.2(3.3)$ & 0.005 \\
\hline Sugar intake $\left(\mathrm{g} \mathrm{day}^{-1}\right)$, mean (SD) & $50(35)$ & $69(49)$ & $142(87)$ & $<0.001$ \\
\hline \% Energy from sugar, mean (SD) & $8.1(4.1)$ & $10.7(5.9)$ & $19.6(10.0)$ & $<0.001$ \\
\hline El/BMR < $1.35(\%)$ & 59 & 58 & 36 & 0.026 \\
\hline BMI $\left(\mathrm{kg} \mathrm{m}^{-2}\right)$, mean (SD) & $25.6(3.5)$ & $25.9(4.2)$ & $25.3(4.2)$ & 0.685 \\
\hline
\end{tabular}

LTPA - leisure-time physical activity; SD - standard deviation; El/BMR - ratio of energy intake to basal metabolic rate.

* Long-term low consumption of sugar-sweetened, carbonated soft drinks is defined as having such beverages less than three times a week in 1991 and 1999, while long-term high consumption is defined as having such beverages three times or more per week in 1991 and 1999 . Inconsistent consumption is defined as those changing their consumption frequency between 1991 and 1999 from low to high or vice versa. † Analysis of variance (UNIANOVA) used to compare consumption groups.

Table 5 Odds ratio $(\mathrm{OR})$ and $95 \%$ confidence interval $(\mathrm{Cl})$ for overweight (body mass index (BMI) $\geq 25 \mathrm{~kg} \mathrm{~m}^{-2}$ ) and obesity (BMI $\geq 30 \mathrm{~kg} \mathrm{~m}^{-2}$ ) in 1999 by long-term (1991-1999) consumption of sugarsweetened, carbonated soft drinks by sex, The Oslo Youth Study

\begin{tabular}{|c|c|c|c|}
\hline & \multirow[b]{2}{*}{$\mathrm{BMI} \geq 25 \mathrm{~kg} \mathrm{~m}^{-2}(\%)$} & \multicolumn{2}{|c|}{ OR $(95 \% \mathrm{Cl})$} \\
\hline & & Model 1 & Model 2 \\
\hline \multicolumn{4}{|l|}{ Women } \\
\hline Long-term low consumers ${ }^{*}(n=116)$ & 28.4 & 1.0 & 1.0 \\
\hline Inconsistent consumers ${ }^{*}(n=50)$ & 24.0 & $0.79(0.37-1.71)$ & $1.26(0.57-3.08)$ \\
\hline Long-term high consumers ${ }^{*}(n=21)$ & 33.3 & $1.26(0.47-3.39)$ & $1.57(0.46-5.33)$ \\
\hline \multicolumn{4}{|l|}{ Men } \\
\hline Long-term low consumers $(n=78)$ & 52.6 & 1.0 & 1.0 \\
\hline Inconsistent consumers $(n=66)$ & 59.1 & $1.30(0.67-2.53)$ & $1.25(0.62-2.55)$ \\
\hline \multirow[t]{3}{*}{ Long-term high consumers $(n=40)$} & 47.5 & $0.82(0.38-1.75)$ & $1.05(0.46-2.40)$ \\
\hline & & \multicolumn{2}{|c|}{ OR $(95 \% \mathrm{Cl})$} \\
\hline & $\mathrm{BMI} \geq 30 \mathrm{~kg} \mathrm{~m}^{-2}(\%)$ & Model 1 & Model 2 \\
\hline \multicolumn{4}{|l|}{ Women } \\
\hline Long-term low consumers $(n=116)$ & 8.6 & 1.0 & 1.0 \\
\hline Inconsistent consumers $(n=50)$ & 8.0 & $0.92(0.28-3.04)$ & $1.98(0.46-8.41)$ \\
\hline Long-term high consumers $(n=21)$ & 9.5 & $1.12(0.23-5.50)$ & $0.80(0.09-6.85)$ \\
\hline \multicolumn{4}{|l|}{ Men } \\
\hline Long-term low consumers $(n=78)$ & 7.7 & 1.0 & 1.0 \\
\hline Inconsistent consumers $(n=66)$ & 9.1 & $1.20(0.37-3.91)$ & $0.52(0.10-2.69)$ \\
\hline Long-term high consumers $(n=40)$ & 10.0 & $1.33(0.35-5.03)$ & $2.29(0.48-10.96$ \\
\hline
\end{tabular}

Model 1 - crude analyses; Model 2 - adjusted for baseline BMI.

* Long-term low consumption of sugar-sweetened, carbonated soft drinks is defined as having such beverages less than three times a week in 1991 and 1999, while long-term high consumption is defined as having such beverages three times or more per week in 1991 and 1999. Inconsistent consumption is defined as those changing their consumption frequency between 1991 and 1999 from low to high or vice versa. 
stability from adolescence into early adulthood found in our study is not in accordance with the study by Lien et $a l^{19}$, as the stability of sugared soft drink intake was high from age 14 to 21 in that study. Some of this discrepancy might be explained by different intake measures and by the longer follow-up period in our study than in Lien et al.'s study. In addition, the measures used in our study, especially in 1981/1979, were crude and differed from the follow-ups. The capability of the questions to rank subjects in the same order has not been investigated, and a difference in the capability of the questions to evaluate subjects' real carbonated soft drinks intake may have influenced the tracking results.

Clustering of unhealthy health behaviours has previously been reported in a number of studies ${ }^{5-7,27,28}$. A negative association between smoking and intake of healthy foods like vegetables and fruits and between smoking and physical activity is observed ${ }^{6,7,28}$. High level of physical activity is also found to be associated with high intakes of healthy foods, and a sedentary lifestyle with a sub-optimal diet ${ }^{5}$. French et $a l^{27}$ found that current smokers increased their soft drinks intake more than did non-smokers during a 2 -year period. The findings in our study, with negative associations between longterm high intake of sugar-sweetened carbonated soft drinks and physical activity and a positive association between soft drinks intake and smoking, support these previous results in that unfortunate health behaviours seem to cluster and that soft drinks intake is a marker of an unhealthy lifestyle.

Consumption of sugar-sweetened soft drinks was found to be positively associated with obesity in a 19-month follow-up among 11- and 12-year-old children'. The authors speculated that energy compensation in a meal following ingestion of energy in liquid form may be less complete than energy compensation in a meal following energy intake from solid foods ${ }^{9}$ - a view supported by other studies ${ }^{10,11,29-31}$. Although the male long-term high consumers of sugar-sweetened, carbonated soft drinks in the present study were found to have higher energy intake than the long-term low consumers, we did not find a significant difference in overweight or obesity between these groups. In the present study, we observed higher energy intake, lower leisure-time physical activity and higher smoking prevalence among long-term high consumers compared with long-term low consumers of sugar-sweetened, carbonated soft drinks. All these factors are associated with body weight and might confound the relationship between soft drinks consumption and obesity. Adjustments for these variables introduced only minor changes in the odds ratios for obesity among longterm high consumers of sugar-sweetened, carbonated soft drinks. It is difficult to adjust fully for all of these factors in the statistical analyses because they are an expression of considerable differences in lifestyle. It will take large studies to make proper adjustments for these related lifestyle factors.

We did observe a higher degree of energy underreporting among long-term low consumers than among long-term high consumers. Underreporting of food intake is shown to be food-specific ${ }^{32,33}$. Several studies have found that food items considered unhealthy and betweenmeal snacks are most likely to be underreported ${ }^{34,35}$. In this study, soft drinks are most likely considered unhealthy by a large proportion of the participants, and therefore intake may have been underreported. Underreporting of soft drinks intake may incorrectly have categorised low consumers as such. Underreporting of energy is also influenced by body weight, with obese subjects more likely than normal-weight subjects to underreport energy intake ${ }^{36}$.

Several studies have found that both men and women underreport body weight and overreport height, which again may contribute to underestimation of $\mathrm{BMI}^{37,38}$. In the 1991 follow-up of The Oslo Youth Study, height and weight were measured among 303 participants. In this sub-sample $85 \%$ of the women and $77 \%$ of the men reported the same height $\pm 1 \mathrm{~cm}$ in 1999 as measured in 1991. The height reported in 1999 was on average 0.4 and $0.3 \mathrm{~cm}$ higher for women and men, respectively, than the height measured in $1991^{39}$. Thus the overestimation of adult height was small. With 8 years between the two surveys in adulthood (at ages 25 and 33), we were not able to validate the reported weight. However, we demonstrated a high degree of tracking of BMI within this sub-sample from 1979 to $1999^{39,40}$. Roberts found that weight was reported without bias in men aged 18-64 years, but that women underreported their weight by $1.1 \mathrm{~kg}$. Reporting was more biased in older and overweight groups ${ }^{41}$. Jeffery found that underreporting of body weight increased with increasing tertiles of weight, but concluded that self-reported body weight is an excellent approximation of actual weight across a broad range of population subgroups ${ }^{42}$. Thus while there might be some underreporting of weight in the present study, we do not consider this a major threat to the investigation of the relationship between soft drinks consumption and body weight.

In 1981/1979, artificially sweetened, carbonated soft drinks were not separated from sugar-sweetened, carbonated soft drinks. This could potentially have caused some misclassification. However, artificially sweetened, carbonated soft drinks constituted only $1-2 \%$ of the total production of carbonated soft drinks in Norway in 1979 and 1981 (H Hasselgård, personal communication, Director of Public Affairs, Association of Brewers and Soft Drink Producers, Norway, 17 June 2003). The reliability of the questions on sugar-sweetened, carbonated soft drinks from the 1991 follow-up survey has been found to be high $(r=0.88)^{43}$. Furthermore, the questionnaire used in 1999 has been validated, and the 
correlation between the questionnaire and 14-day weighed records was 0.66 for added sugar ${ }^{22}$ and 0.67 for sugar-sweetened, carbonated soft drinks (L Frost Andersen, personal communication, Post Doctoral Fellow, Department of Nutrition, University of Oslo, 31 January 2003). Sugared fruit drinks intake is not included in the tracking analyses, as we only have reliable measures of such intake in 1999.

In this study, the subjects included were those who responded to all three surveys during the 18-20-year time period, resulting in a relatively large attrition rate. Furthermore, stratifying the subjects into men and women and low and high consumers resulted in relatively small groups and reduced statistical power. As a result, only pronounced differences between groups would be identified as significant. In spite of this and the fact that different survey questions were used to assess soft drinks consumption in this study, pronounced differences were found between long-term low and high consumers of sugar-sweetened, carbonated soft drinks with respect to intake of such beverages, sugar and proportion of energy from sugar in 1999. Thus, the magnitude of these differences as well as of differences in physical activity, smoking and energy intake may be at least as large as those indicated by the findings in this study.

The proportions of men and of smokers in 1981/1979 were smaller among participants than among those who dropped out of the study. No differences were found with respect to BMI or sugar-sweetened, carbonated soft drinks intake. The difference in gender distribution between participants and drop-outs will not affect the results in this study as men and women were analysed separately. As stability of smoking is shown to be high ${ }^{44}$, it is likely that there were more non-smokers among participants than among drop-outs in 1999. The potential weight-increasing effect of sugary soft drinks will most likely be counteracted by the weight-reducing effect of smoking ${ }^{45}$. As there were more smokers among participants who dropped out of the study than among the cohort participants, a potential association between sugary soft drinks intake and BMI could be weakened if more of the smoking drop-outs were included in the analyses. With respect to the observed soft drinks intake in 1999, our findings are comparable to the Norwegian Norkost study that reported the intake of sugar-sweetened soft drinks (both carbonated and squash/syrup) in 1997 to be $569 \mathrm{~g} \mathrm{day}^{-1}$ for men aged 16-29 years and $212 \mathrm{~g} \mathrm{day}^{-1}$ for men aged 30-59 years. Corresponding figures for women were 292 and $126 \mathrm{~g}$ daily ${ }^{46}$. Thus, the high attrition rate seen in this study is not considered a major threat to the validity of the findings presented.

\section{Conclusion}

This study showed high stability of sugar-sweetened, carbonated soft drinks intake from early adulthood into later adulthood, but the stability from adolescence and into later adulthood was low. Long-term high intake of sugar-sweetened carbonated soft drinks was associated with reduced level of leisure-time physical activity among women and with increased smoking prevalence and increased energy intake among men, compared with having a long-term low intake of soft drinks. However, long-term soft drinks consumption was not significantly associated with adult rates of overweight or obesity. Due to measurement limitations in the present study, as well as the current secular trend of increasing soft drinks consumption, we recommend that this issue be investigated further in large, prospective cohort studies applying consistent and validated intake measures.

\section{Acknowledgements}

The Oslo Youth Study was supported by The Norwegian Cancer Society. This research was supported with a grant from the EXTRA funds from the Norwegian Foundation for Health and Rehabilitation.

\section{References}

1 Astrom AN, Samdal O. Time trends in oral health behaviors among Norwegian adolescents: 1985-97. Acta Odontologica Scandinavica 2001; 59: 193-200.

2 Johansson L. Development in Dietary Intake in Norway. Oslo: National Council for Nutrition and Physical Activity, 2002.

3 Øverby NC, Andersen LF. Ungkost - 2002. Oslo: Directorate for Health and Social Affairs, 2002.

4 Popkin BM, Nielsen SJ. The sweetening of the world's diet. Obesity Research 2003; 11: 1325-32.

5 Gillman MW, Pinto BM, Tennstedt S, Glanz K, Marcus B, Friedman RH. Relationships of physical activity with dietary behaviors among adults. Preventive Medicine 2001; 32: 295-301.

6 Kvaavik E, Meyer HE, Tverdal A. Food habits, physical activity and body mass index in relation to smoking status in 40-42 year old Norwegian women and men. Preventive Medicine 2004; 38: 1-5.

7 Laaksonen M, Prattala R, Karisto A. Patterns of unhealthy behaviour in Finland. European Journal of Public Health 2001; 11: 294-300.

8 James J, Thomas P, Cavan D, Kerr D. Preventing childhood obesity by reducing consumption of carbonated drinks: cluster randomised controlled trial. British Medical Journal 2004; 328: 1237.

9 Ludwig DS, Peterson KE, Gortmaker SL. Relation between consumption of sugar-sweetened drinks and childhood obesity: a prospective, observational analysis. Lancet 2001; 357: 505-8.

10 Raben A, Vasilaras TH, Moller AC, Astrup A. Sucrose compared with artificial sweeteners: different effects on ad libitum food intake and body weight after $10 \mathrm{wk}$ of supplementation in overweight subjects. American Journal of Clinical Nutrition 2002; 76: 721-9.

11 Tordoff MG, Alleva AM. Effect of drinking soda sweetened with aspartame or high-fructose corn syrup on food intake and body weight. American Journal of Clinical Nutrition 1990; 51: 963-9.

12 World Health Organization (WHO)/Food and Agriculture Organization (FAO). Diet, Nutrition and the Prevention of 
Chronic Diseases. Report of a WHO/FAO Expert Consultation. Technical Report Series No. 916. Geneva: WHO, 2003.

13 Lewis CE, Jacobs DR Jr, McCreath H. Weight gain continues in the 1990s: 10-year trends in weight and overweight from the CARDIA study. Coronary Artery Risk Development in Young Adults. American Journal of Epidemiology 2000; 151: 1172-81.

14 Livingstone MB. Childhood obesity in Europe: a growing concern. Public Health Nutrition 2001; 4: 109-16.

15 Tverdal A. Prevalence of obesity among persons aged 40-42 years in two periods. Tidsskrift for den Norske Laegeforening 2001; 121: 667-72 [in Norwegian].

16 Kelder SH, Perry CL, Klepp KI, Lytle LL. Longitudinal tracking of adolescent smoking, physical activity, and food choice behaviors. American Journal of Public Health 1994; 84: $1121-6$.

17 Post GB, de Vente W, Kemper HC, Twisk JW. Longitudinal trends in and tracking of energy and nutrient intake over 20 years in a Dutch cohort of men and women between 13 and 33 years of age: The Amsterdam Growth and Health Longitudinal Study. British Journal of Nutrition 2001; 85: 375-85.

18 Cusatis DC, Chinchilli VM, Johnson-Rollings N. Longitudinal nutrient intake patterns of US adolescent women: the Penn State Young Women's Health Study. Journal of Adolescent Health 2000; 26: 194-204.

19 Lien N, Lytle LA, Klepp KI. Stability in consumption of fruit, vegetables, and sugary foods in a cohort from age 14 to age 21. Preventive Medicine 2001; 33: 217-26.

20 Welten DC, Kemper HC, Post GB. Longitudinal development and tracking of calcium and dairy intake from teenager to adult. European Journal of Clinical Nutrition 1997; 51: 612-8.

21 Klepp K-I, Øygard L, Tell GS, Vellar OD. Twelve year followup of a school-based health education programme. The Oslo Youth Study. European Journal of Public Health 1994; 4: 195-200.

22 Andersen LF, Solvoll K, Johansson LR. Evaluation of a food frequency questionnaire with weighed records, fatty acids, and alpha-tocopherol in adipose tissue and serum. American Journal of Epidemiology 1999; 150: 75-87.

23 Nes M, Frost AL, Solvoll K. Accuracy of a quantitative food frequency questionnaire applied in elderly Norwegian women. European Journal of Clinical Nutrition 1992; 46: 809-21.

24 Food and Agriculture Organization (FAO)/World Health Organization (WHO)/United Nations University (UNU). Energy and Protein Requirements. Report of a Joint $\mathrm{FAO} / \mathrm{WHO} / \mathrm{UNU}$ Expert Consultation. Technical Report Series No. 724. Geneva: WHO, 1985

25 Black AE. Critical evaluation of energy intake using the Goldberg cut-off for energy intake:basal metabolic rate. A practical guide to its calculation, use and limitations. International Journal of Obesity and Related Metabolic Disorders 2000; 24: 1119-30.

26 Goldberg GR, Black AE, Jebb SA. Critical evaluation of energy intake data using fundamental principles of energy physiology: 1. Derivation of cut-off limits to identify underrecording. European Journal of Clinical Nutrition 1991; 45 : 569-81.

27 French SA, Hennrikus DJ, Jeffery RW. Smoking status, dietary intake, and physical activity in a sample of working adults. Health Psychology 1996; 15: 448-54.

28 Schuit AJ, van Loon AJ, Tijhuis M, Ocke M. Clustering of lifestyle risk factors in a general adult population. Preventive Medicine 2002; 35: 219-24.
29 Beridot-Therond ME, Arts I, Fantino M. Short-term effects of the flavour of drinks on ingestive behaviours in man. Appetite 1998; 31: 67-81.

30 De Castro JM. The effects of the spontaneous ingestion of particular foods or beverages on the meal pattern and overall nutrient intake of humans. Physiology \& Behavior 1993; 53: 1133-44.

31 Mattes RD. Dietary compensation by humans for supplemental energy provided as ethanol or carbohydrate in fluids. Physiology \& Behavior 1996; 59: 179-87.

32 Goris AH, Westerterp-Plantenga MS, Westerterp KR. Undereating and underrecording of habitual food intake in obese men: selective underreporting of fat intake. American Journal of Clinical Nutrition 2000; 71: 130-4.

33 Voss S, Kroke A, Klipstein-Grobusch K, Boeing H. Is macronutrient composition of dietary intake data affected by underreporting? Results from the EPIC-Potsdam Study. European Prospective Investigation into Cancer and Nutrition. European Journal of Clinical Nutrition 1998; 52 : 119-26.

34 Lafay L, Mennen L, Basdevant A. Does energy intake underreporting involve all kinds of food or only specific food items? Results from the Fleurbaix Laventie Ville Sante (FLVS) study. International Journal of Obesity and Related Metabolic Disorders 2000; 24: 1500-6.

35 Poppitt SD, Swann D, Black AE, Prentice AM. Assessment of selective under-reporting of food intake by both obese and non-obese women in a metabolic facility. International Journal of Obesity and Related Metabolic Disorders 1998; 22: 303-11.

36 Heerstrass DW, Ocke MC, Bueno-de-Mesquita HB. Underreporting of energy, protein and potassium intake in relation to body mass index. International Journal of Epidemiology 1998; 27: 186-93.

37 DelPrete LR, Caldwell M, English C. Self-reported and measured weights and heights of participants in communitybased weight loss programs. Journal of the American Dietetic Association 1992; 92: 1483-6.

38 Niedhammer I, Bugel I, Bonenfant S. Validity of self-reported weight and height in the French GAZEL cohort. International Journal of Obesity and Related Metabolic Disorders 2000; 24: 1111-8.

39 Kvaavik E, Tell GS, Klepp KI. Stability of body mass index from adolescence to adulthood. Tidsskrift for den Norske Laegeforening 2002; 122: 894-900 [in Norwegian].

40 Kvaavik E, Tell GS, Klepp KI. Predictors and tracking of body mass index from adolescence into adulthood: follow-up of 18 to 20 years in the Oslo Youth Study. Archives of Pediatrics E Adolescent Medicine 2003; 157: 1212-8.

41 Roberts RJ. Can self-reported data accurately describe the prevalence of overweight? Public Health 1995; 109: 275-84.

42 Jeffery RW. Bias in reported body weight as a function of education, occupation, health and weight concern. Addictive Behaviors 1996; 21: 217-22.

43 Skårer C. A method evaluation of questions asked at age 16-, 18-, and 19 years in The Norwegian Longitudinal Health Behaviour Study. Master thesis, Department of Nutrition, University of Oslo, 2001 [in Norwiegan].

44 Chassin L, Presson CC, Sherman SJ, Edwards DA. The natural history of cigarette smoking: predicting young-adult smoking outcomes from adolescent smoking patterns. Health Psychology 1990; 9: 701-16.

45 Perkins KA. Weight gain following smoking cessation. Journal of Consulting and Clinical Psychology 1993; 61: $768-77$.

46 Johansson L, Solvoll K. Norkost 1997. Oslo: Directorate for Health and Social Affairs, 1999 [in Norwegian]. 